\title{
Construção de espaços públicos em Bogotá e Rio de Janeiro: uma análise comparada dos projetos públicos durante a década de 1990
}

Construction of public spaces in Bogotá and Rio de Janeiro: a comparative analysis of public projects during the 1990s

Ana Marcela Ardila Pinto

\section{Resumo}

A partir da década de 1990, em diversas cidades latino-americanas foram realizados projetos de requalificação e revitalização urbana no marco do denominado modelo de planejamento estratégico catalão. Em Bogotá e no Rio de Janeiro, foi privilegiada a criação de áreas públicas no intuito de fortalecer a vida democrática e o convívio entre os cidadãos. Esses projetos foram promovidos principalmente durante as prefeituras de Antanas Mockus e Enrique Peñalosa em Bogotá, e de Cesar Maia e Luiz Conde, no Rio de Janeiro. Comparamos a apropriação do modelo nos dois contextos locais, baseados na análise dos investimentos públicos e dos tipos de projetos de intervenção no espaço urbano, no intuito de evidenciar o processo de ressignificação na escala local deste modelo.

Palavras-chave: espaço público; Bogotá; Rio de Janeiro; política urbana; escala.

\begin{abstract}
Since the 1990s, regeneration, renovation and revitalization projects of urban areas have been developed in several Latin American cities, based on the Barcelona model of strategic planning. It was the case of Bogotá and Rio de Janeiro, where local authorities promoted the creation of public areas in order to strengthen the democratic life and sociability among citizens. These projects were promoted mainly during the local government of Antanas Mockus and Enrique Peñalosa, in Bogotá, and Cesar Maia and Luiz Conde, in Rio de Janeiro. We compared the appropriation of the model in the two local contexts, based on an analysis of public investments and types of intervention projects in urban areas, aiming to examine the process of resignification of this model at the local level.
\end{abstract}

Keywords: public space; Bogotá; Rio de Janeiro; urban policy; scale. 


\section{Introdução}

Como em outras cidades europeias e latino-americanas, os governos locais de Bogotá e do Rio de Janeiro experimentaram transformações similares nas suas formas de gerir e intervir seus espaços urbanos. Ao longo da década de 1990 e, em parte da seguinte, os agentes públicos decidiram incorporar propostas de um modelo de produção da cidade que rapidamente conseguiu uma posição relevante no campo do planejamento e da gestão urbana. Trata-se do planejamento estratégico catalão, inspirado na experiência de renovação urbana de Barcelona. A promoção desse modelo sob a égide de experts catalães, através do Centro Ibero-americano de Desarrollo Estratégico Urbano (Cideu, 2004), da prefeitura de Barcelona, foi apoiado e difundido ativamente por organismos multilaterais como a agência Hábitat das Nações Unidas e o Banco Interamericano de Desenvolvimento (Duque, 2008).

Entre outros princípios, autores como Jordi Borja (Borja e Muxi, 2003), um dos principais promotores do modelo, valorizaram a realização de projetos de intervenção em detrimento de grandes planos de ordenamento e zoneamento urbano; a flexibilização normativa e a mistura de usos urbanos, em lugar da especialização funcional das áreas; a participação entre agentes públicos e privados na gestão urbana em oposição ao planejamento estatal ou à primazia dos grandes agentes privados; a revalorização e a densificação do espaço urbano construído no lugar da expansão suburbana; e a preferência pelo transporte público em detrimento ao automóvel privado.

Uma das estratégias centrais desse modelo foi a criação de espaços públicos, com a qual se esperava atingir diversos objetivos. Em termos urbanísticos, procurava-se viabilizar a requalificação de áreas degradadas, a melhoria da mobilidade e da acessibilidade, a recuperação de áreas centrais, a reintegração dos tecidos urbanos, o reordenamento dos usos e a definição dos processos de crescimento e expansão da cidade. Em termos econômicos, os efeitos esperados abrangeram o aumento da produtividade e da competitividade urbana, a dinamização do setor privado e a diminuição dos gastos públicos em um contexto de forte concorrência por atrair recursos globais. Em relação aos objetivos políticos e sociais, esses projetos procuraram promover o aumento da legitimidade do Estado e o desenvolvimento da cidadania, no marco dos processos de redemocratização e descentralização política. Além disso, eles procuraram estimular o encontro social e reforçar o papel das artes e dos elementos simbólicos da identidade urbana (Berdoulay e Morales, 1999, p. 89).

Espaços antes considerados como elementos decorativos, luxos desnecessários, ou quesitos acessórios nos orçamentos das grandes obras de infraestrutura, foram concebidos como intervenções fundamentais e legítimas para transformar a paisagem urbana. De fato, o sucesso do modelo ganhou visibilidade a partir da realização dos jogos olímpicos em 1992, em Barcelona. Isso se deu com a renovação de praças com vistas à requalificação das antigas e degradadas áreas do centro, do porto e das estações ferroviárias, e por meio da abertura de avenidas e do aproveitamento de velhas infraestruturas viárias, com a reconversão de vias rápidas em alamedas para pedestres e a criação de parques urbanos, jardins, logradouros e novos equipamentos. 
Para os agentes políticos sul-americanos, o modelo catalão constituiu uma experiência replicável nas suas próprias realidades locais (Borja e Muxi, 2003). Tal foi o caso dos agentes locais cariocas e bogotanos, os quais conferiram ao espaço público um papel central na transformação e revitalização do espaço urbano, especialmente naquelas áreas degradadas dos centros ou em espaços "sem função". Os agentes também consideraram que esse conjunto de intervenções aumentaria a integração social e fortaleceria o sentido de pertencimento à comunidade urbana por meio da criação de referências identitárias. Além disso, essas ações foram entendidas como meios para aperfeiçoar as diferentes funções e estruturas urbanas, como a mobilidade e a acessibilidade, a preservação do patrimônio ambiental e cultural e o controle do crescimento, o que poderia ser visto como um fator para incrementar a competitividade da cidade. Entretanto, essas semelhanças em relação ao papel do espaço público nas duas cidades terão desdobramentos diferenciados na construção de um conjunto de políticas relativas a aspectos como o controle, o uso e a apropriação desses cenários pelos cidadãos. 0 objetivo deste trabalho é comparar o desenvolvimento dessas políticas de espaço público nessas duas cidades, no intuito de estabelecer as continuidades e descontinuidades em relação ao valor que os agentes locais atribuíram ao espaço público em diferentes instrumentos de política pública local.

Queremos defender a ideia de que ainda que tenham sido adotados alguns dos lineamentos do modelo, há diferenças importantes na construção do conceito de espaço público e das políticas urbanas em cada contexto local. As evidências de ressignificações locais desses modelos globais nos permitem discutir a visão de autores que têm privilegiado o determinismo da escala global na explicação de sua apropriação e têm salientado a homogeneidade na implementação dos projetos em diversos contextos urbanos. Em Bogotá, tanto os arranjos normativos como as ações de governo se integraram em uma política que define o espaço público como o conceito estruturante do modelo de ordenamento; enquanto no Rio de Janeiro essa categoria esteve mais atrelada a uma visão conjuntural, no marco dos projetos promovidos sob a égide do planejamento estratégico, e no privilégio de intervenções mais pontuais.

Para a realização deste trabalho não partiremos de uma visão normativa ou conceitual a priori sobre a definição do espaço público. Pelo contrário, queremos identificar como foi definida essa categoria pelos agentes urbanos locais, e como essa definição intervém na implantação das políticas locais urbanas. Empregaremos dois tipos de fontes, que, apesar de apresentarem limitações para compreender 0 conjunto das políticas, constituem indicadores relevantes que têm sido pouco trabalhados, para determinar a importância que tiveram os investimentos nesse tipo de espaços e as diferenças locais no desenvolvimento desses projetos: os investimentos, o tipo de intervenção e seus arranjos espaciais.

Dividiremos o trabalho em três partes. $\mathrm{Na}$ primeira, identificam-se os critérios teóricos e metodológicos que orientaram a realização do trabalho. Na segunda, procura-se identificar 0 papel do espaço público nos orçamentos locais em cada cidade, tanto em comparação com outros setores de política, como em termos temporais no período de estudo. Na terceira, apresenta-se uma análise dos arranjos espaciais 
dos projetos de espaço público desenvolvidos em cada cidade, em relação ao número, tipo de objeto urbano produzido e localização. São considerados os casos de Bogotá entre 1995 e 2004, nas gestões dos prefeitos Antanas Mockus (1995-1997 e 2001-2004) e Enrique Peñalosa (1998-2000); e do Rio de Janeiro entre 1992 e 2008, nas prefeituras de César Maia (1993-1996, 2001-2004 e 2005-2008) e de Luiz Conde (1997 - 2000). Foi durante esses períodos que esses gestores urbanos aderiram às propostas dos especialistas barceloneses.

\section{Alguns critérios para a análise dos projetos de espaço público}

Uma das hipóteses mais influentes para a explicação da produção de projetos de espaço público no campo da pesquisa urbana é aquela defendida por autores como David Harvey (1996), Neil Smith e Setha Low (2006), Christine Boyer (1992), Sharon Zukin (1995) e Don Mitchell (2003), para os quais essas intervenções realizadas no marco do modelo de planejamento estratégico são realizadas fundamentalmente para gerar uma imagem positiva das cidades e condições favoráveis para atrair o capital transnacional, no intuito de criar uma marca de cidade no contexto de globalização econômica e cultural. Esta estratégia, denominada city marketing, procura promover a localização de negócios e elites corporativas no marco de uma intensa concorrência para atrair o capital global.

Os espaços criados no marco do planejamento estratégico, denominados como semipúblicos, ou pseudo-públicos, se distinguem, de acordo com os autores desse grupo, pela progressiva privatização na sua produção, gestão e manutenção. Longe da ideia do público como possibilidade de livre acesso e encontro dos cidadãos, eles se transformam em símbolos culturais da ação do grande capital, referentes, marcas de reconhecimento econômico ou, em outras palavras, mercadorias. Constituem, assim, formas de manipulação simbólica para a afirmação dos valores burgueses dos empresários, investidores e funcionários, e, em consequência, a exclusão de grupos sociais considerados marginais. Caracterizam-se pela sua homogeneidade, pela promoção de uma estética baseada no pós-modernismo e pela localização em áreas de interesse da valorização dos empresários imobiliários. A produção desses espaços foi pesquisada sob essa mesma perspectiva, entre outros muitos exemplos, para cidades como Nova York por Sharon Zukin (1995) e Christine Boyer (1992); Barcelona por Ana Ortiz (2006) ou Adriano Botelho (2004); San Diego, Miami, Orlando, Phoenix e Jacksonville por Robyne Turner (2002). Para o caso das cidades latino-americanas, pode-se lembrar o estudo de Daniel Hiernaux (2006) para cidade de México; e de Pablo Ciccolella para Buenos Aires (1999).

Essa visão orientou grande parte das pesquisas realizadas, especialmente para 0 caso do Rio de Janeiro. Os trabalhos sobre os projetos de espaço público salientaram o desenvolvimento desse modelo e seus efeitos para a autonomia do setor público, a integração da cidade com os mercados globais, a participação dos movimentos sociais na formulação e execução das políticas, entre outros. Alguns estudos procuraram destacar o problema da 
participação dos agentes privados na gestão urbana (Bienenstein, 2000; Sartor, 2001), a intervenção catalã e o planejamento estratégico na formulação do projeto (Pires, 2010), os problemas da restrição da participação social (Olivera, 2008), a gestão ineficiente e os altos custos das obras (Domingues, 1999). Outras pesquisas enfatizam o uso das obras de infraestrutura no marco de uma estratégia de marketing político e de atração de investimentos externos (Machado, 2003) ou os impactos do projeto no mercado imobiliário (Pulici, 2006).

Diferente do caso brasileiro, em Bogotá os estudos discutiram o papel do espaço público em termos de problemáticas de ordem mais local. As intervenções foram concebidas como um fenômeno mais específico atrelado aos problemas de desordem urbana e enquadradas em uma política urbana orientada para o fortalecimento da gestão local. Um grupo importante de pesquisadores considerou esses projetos no marco da emergência de uma nova tendência de planejamento que reivindica o urbanismo público (Salazar, 2008; Pardo, 2008). Outros autores explicam seu desenvolvimento a partir das transformações institucionais das reformas da Constituição Política de 1991, dos processos de descentralização e do colapso da máquina política clientelista na década de 1990 (Santos, 2007) ou procuram estabelecer os impactos dessas políticas sobre os processos de formação da cidadania (Cubaque, 2009).

Comparativamente, em relação ao caso carioca, pode-se afirmar que se privilegiaram perspectivas que concedem à escala global e à expansão do capitalismo um fator explicativo determinante. Supõe-se que processos iguais têm efeitos iguais em contextos geográficos e socioeconômicos tão diferenciados como as cidades europeias, norte-americanas ou latino-americanas. Consideramos que ainda que a globalização e o capitalismo pareçam ser elementos necessários para entender o fenômeno, não são suficientes para entender como são apropriados os modelos urbanísticos. No caso bogotano, por se tratarem de estudos de caso, naturalizam as intervenções como processos estritamente locais, desconhecendo o papel dos agentes globais na produção e difusão de modelos urbanos. Em ambos os casos, há uma primazia da escala, seja global ou local, como critério de explicação do fenômeno.

Essa perspectiva determinística da escala como forma de explicação tem sido bastante criticada, especialmente a partir da década de 2000. Enquanto a maior parte dos debates salientava o papel homogeneizador do capitalismo, produto de sua expansão global, particularmente no período pós-fordista, uma nova geração de geógrafos discutiu esse caráter determinista da explicação dos fenômenos. Autores como Swyngedouw (2008), Moore (2008), Howitt (2003) e Brenner (1998), entre outros, consideram a escala como uma construção social, produto dos balanços de poder entre diferentes agentes sociais. Assim, as formas de organização social e os arranjos espaciais produzidos pelos agentes, no marco de diversas relações de poder, configuram novas escalas para os fenômenos e são, ao mesmo tempo, reguladas por essas. A constituição da escala não é fixa, nem unívoca e pode ser remodelada em seu conteúdo, importância e relação. Dessa forma, dependendo de cada fenômeno, é possível observar um arranjo diferenciado das escalas, segundo as formas de participação de cada um dos agentes, em que cada 
uma tem os seus limites e possíveis aberturas para a ação (Swyngedouw, 2008, p. 133).

A partir de um estudo comparado sobre a construção dos projetos de espaço público é possível observar como os agentes políticos especializados de cada cidade apropriaram-se dos critérios promovidos pelo planejamento estratégico difundido globalmente e os recontextualizaram em diálogo com as realidades e as demandas dos agentes locais. Achamos que, ao mesmo tempo em que há continuidades nos discursos, práticas e estratégias empregadas pelos agentes urbanos globais, há também fortes diferenças locais. É precisamente pelo fato de que há uma intensa relação entre as escalas globais e locais que não é possível considerar um movimento de homogeneização e imposição de um modelo espacial e político único, nem seu caráter sui generis.

Para a realização da pesquisa comparada destas duas cidades, definimos alguns critérios metodológicos. 0 primeiro deles diz respeito à fonte de observação da política pública urbana, tendo em vista a multiplicidade de instrumentos que o Estado dispõe para intervir na produção do espaço urbano. Segundo Corrêa (1995), a maior parte desses instrumentos abrange ações de regulação, imposição de tributo e ordenamento da atividade dos agentes privados, impondo limitações sobre os direitos de edificar. Esses instrumentos são mediados por modelos e arranjos normativos de outras escalas, ainda que sejam ressignificados pelos agentes políticos locais, objeto de interesse deste trabalho.

Para compreender a classificação local da categoria de espaço público, comparando-a a outros bens que são de investimento obrigatório como é o caso da educação e da saúde, optou-se por analisar ferramentas de planejamento e de gestão nas quais os agentes locais conseguem exercer um maior grau de autonomia. Foram contemplados os investimentos públicos locais associados às intervenções urbanas consideradas pelos agentes locais como espaço público. Os tipos de informação considerados na pesquisa das duas cidades foram os seguintes:

a) Tipo e localização dos projetos de intervenção de espaço público nos programas de governo, manuais de construção, orçamentos de instituições responsáveis pela sua produção. A informação concernente ao projeto de espaço público carioca, denominado Rio Cidade, foi fornecida pela Riourbe, Empresa Municipal de Urbanização e pela Coordenadoria Geral de Obras (CGO), órgãos da Secretaria Municipal de Obras. Para Bogotá, utiliza-se a informação dos Planes Operativos de Inversión, POAI, do Instituto de Desarrollo Urbano, IDU, órgão da prefeitura cuja função é a construção e recuperação dos espaços públicos da cidade.

b) As despesas anuais de cada prefeitura para cada período de governo dos quatro prefeitos, baseadas no cálculo da distribuição de investimentos e as despesas anuais por setor de governo. No caso do Rio de Janeiro, as observações abrangem o período compreendido entre 1993 e 2008. Para Bogotá, entre 1995 e 2004.

c) As despesas destinadas à produção de projetos de espaço público, com informação relativa aos custos e à localização de cada um deles. No caso de Bogotá se teve acesso às informações relativas à repartição geográfica das despesas para o primeiro período de governo de Antanas Mockus, razão pela qual se apresentam somente os dados relativos ao período de 1998 até 2004. As despesas foram todas 
expressas em valores correntes de 2008, com base nos dados do Índice de Preços ao Consumidor da Fundação Getúlio Vargas no caso carioca e, no caso de Bogotá, do Banco de la República de Colombia.

\section{Resultados}

\section{0 espaço público como bem prioritário nos orçamentos locais}

A partir da análise das despesas, é possível observar que, nas duas cidades, os prefeitos priorizaram o espaço público como investimento ao longo do período. Pode se dizer que houve uma apropriação na gestão urbana dos critérios de ordenamento urbano do planejamento estratégico catalão. Porém, essa apropriação não foi mecânica; é possível identificar que o peso no conjunto das despesas tem importantes diferenciações no valor atribuído pelos agentes locais cariocas e bogotanos.

No Rio de Janeiro, as despesas com espaço público foram incluídas na função de habitação e urbanismo, o que permite um entendimento mais fácil das tendências durante os quatro períodos de governo. No caso de Bogotá, a mesma definição desse bem público pode aparecer distribuída em várias funções, embora a maior parte esteja alocada no setor de transporte e obras viárias, associada à execução do projeto de transporte de massa, Transmilenio, e no setor de cultura, lazer e esporte, na produção de parques urbanos. Nos seguintes gráficos, é possível observar a evolução das despesas segundo função de governo nas duas cidades. São excluídos nos dois casos os valores de educação, saúde e saneamento básico, pois o limite inferior de participação no orçamento local é definido pelas leis nacionais, e os prefeitos têm poucas opções para lhes atribuir um peso menor. ${ }^{1}$

No Rio de Janeiro, o setor de habitação e urbanismo, que incorpora os investimentos com o projeto Rio Cidade (além da construção da via expressa Linha Amarela), teve um papel relevante ao longo do período (com uma média de $27,6 \%$ ), se comparado com transporte, esporte e lazer e outros, que agrupa assistência e previdência, indústria, comércio e trabaIho. ${ }^{2}$ Esse papel só é superado pelas despesas em governo a partir de 1997 (com média de $31,3 \%$ nos setores judiciário, legislativo, segurança e administração pública e planejamento). A participação mais importante do setor corresponde ao primeiro período de governo de César Maia, dado que no governo de Conde e nos restantes de Maia atingiu uma porcentagem menor, próxima de $20 \%$ (Gráfico 1). No setor de esporte e lazer, pode-se observar um leve aumento das despesas a partir de 2002, e especialmente entre 2005 e 2007, como decorrência da participação da cidade como sede dos Jogos Pan-americanos.

Diferentemente do Rio de Janeiro, o comportamento geral das curvas em Bogotá é muito mais estável, demonstrando uma maior continuidade na execução dos investimentos. Pode-se observar no Gráfico 2 um aumento importante do fluxo de recursos para o setor de transporte ao longo do período, especialmente a partir de 1997, quando se inicia o governo de Enrique Peñalosa (uma média de 35\% no total). Esse setor abrange o Transmilenio, que foi definido como um projeto de espaço público e mobilidade urbana e incorpora, de forma 
Gráfico 1 - Distribuição percentual das despesas por função de governo no Rio de Janeiro entre 1991 e 2008

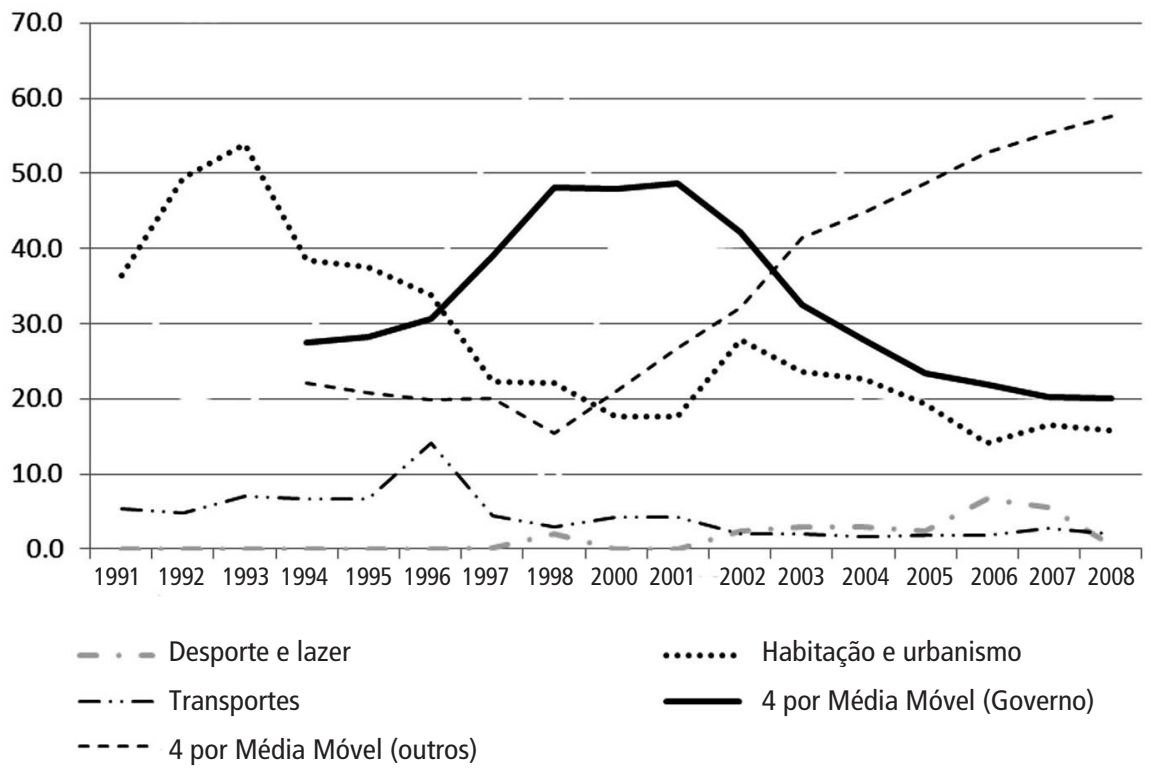

Fontes: Elaboração própria baseada em dados do IPP (1998) para 1992-1998.

Controladoria Geral do Município do Rio de Janeiro (2010) para 2001 e 2008.

\section{Gráfico 2 - Distribuição percentual das despesas por função de governo em Bogotá entre 1995 e 2005}

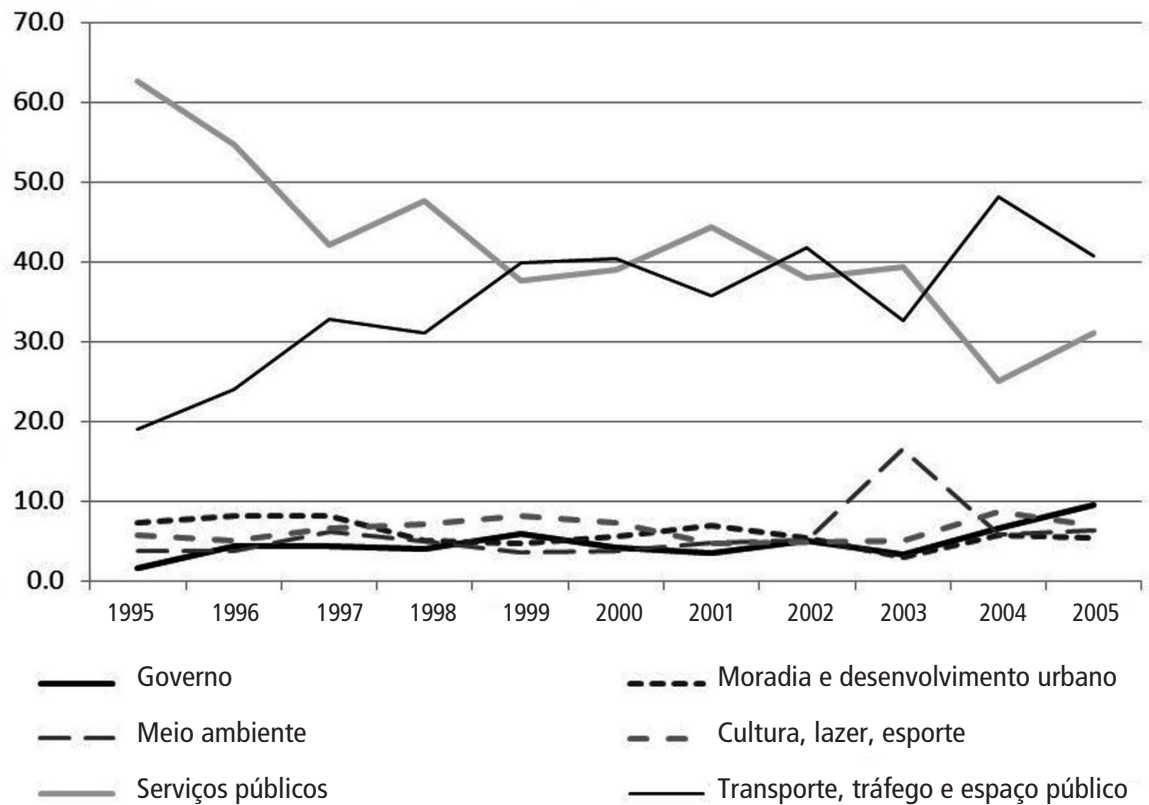

Fontes: Cálculos próprios baseados em dados da Câmara de Comércio de Bogotá (2005). 
estrutural em seu desenho, uma importante quantidade de áreas públicas para pedestres, de transição entre a via e os outros usos, facilidades para pessoas com mobilidade reduzida, entre outras. 0 caso do setor de cultura, lazer e esportes, que inclui a construção de parques, apresentou um aumento também no governo de Peñalosa, diminuiu durante o de Antanas Mockus, para depois aumentar de novo no governo seguinte. Os investimentos no setor apresentaram uma média total de $6,4 \%$ durante todo o período, superior àquela de setores como ambiente, moradia e governo.

Para compreender de forma mais específica a participação do espaço público nos investimentos das duas cidades, realizou-se uma análise das despesas de capital executadas nos períodos de governo dos quatro prefeitos. Para as duas cidades, foi empregada a série de despesas de capital, para o Rio de Janeiro do IPEA (2011) e para Bogotá da Cámara de Comercio (2005). Os dados foram deflacionados para valores de 2008 e, nesse caso somente, foram considerados os dados relativos à Secretaria de Obras Públicas do Rio de Janeiro e ao IDU de Bogotá. ${ }^{3}$

Os dados disponíveis permitem assinalar algumas tendências importantes. De forma mais geral, a participação dos projetos nas despesas de capital nas duas cidades foi similar. Durante o período analisado, os prefeitos bogotanos despenderam $10,4 \%$ do total de investimentos na produção de calçadas, passarelas, praças, instalação de mobiliário, calçadões e vários projetos de requalificação urbana no centro da cidade. No Rio, para o projeto Rio
Cidade foram gastos $9,2 \%$ do total das despesas de capital. Apesar da similaridade na proporção dos investimentos, há diferenças em relação a sua distribuição no tempo. No Rio de Janeiro, a maior parte (mais de $40 \%$ ) foi investida durante o primeiro governo de Maia. Nas gestões seguintes, essas despesas não atingiram sequer $10 \%$ do total das despesas de capital. Durante o primeiro período foram investidos mais de $\mathrm{R} \$ 480$ milhões de reais. No ano seguinte, as despesas alcançaram $\mathrm{R} \$ 343$ milhões, o equivalente a apenas 9,5\% do total de investimentos. No último período registra-se uma forte queda na proporção investida nesses projetos, atingindo $\mathrm{R} \$ 16$ milhões, valor equivalente a $0.4 \%$ do total das despesas (superior a quatro bilhões de reais).

Em Bogotá, durante o governo de Enrique Peñalosa, investiu-se a maior proporção de recursos em projetos de espaço público, mais de 2.700 milhões de pesos. No governo seguinte, de Mockus, essa participação apresentou uma redução drástica e atingiu apenas $6 \%$ (885 milhões de pesos) do total das despesas de capital, mas não desapareceu como praticamente aconteceu no caso carioca.

Esses dados evidenciam que os projetos de espaço público foram valorizados nas preferências de investimentos dos agentes públicos locais nas duas cidades, ainda que com diferenças significativas nos ritmos e na própria definição do que se denominaria como projeto de espaço público. Essas diferenças também são relevantes ao se observar os tipos de intervenção realizados em cada cidade e os critérios de sua implantação. 
Gráfico 3 - Participação porcentual dos investimentos em espaços públicos no total das despesas de capital no Rio de Janeiro entre 1993 e 2008 (Projetos Rio Cidade e Urbe Cidade)

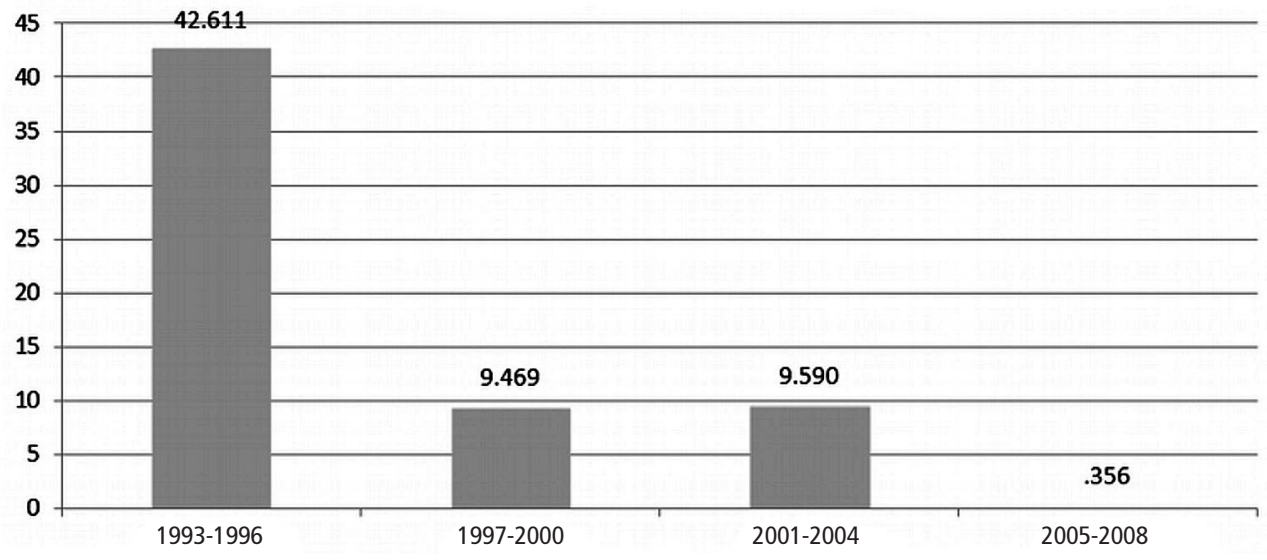

Fontes: Elaboração própria baseada nos dados de despesa do Ipea e comunicação pessoal com funcionários da Riourbe, Empresa Municipal de Urbanização e Coordenadoria Geral de Obras (CGO) da Secretaria de Obras Públicas do Rio de Janeiro.

\section{Gráfico 4 - Participação porcentual dos investimentos em espaços públicos} no total das despesas de capital em Bogotá entre 1995 e 2004

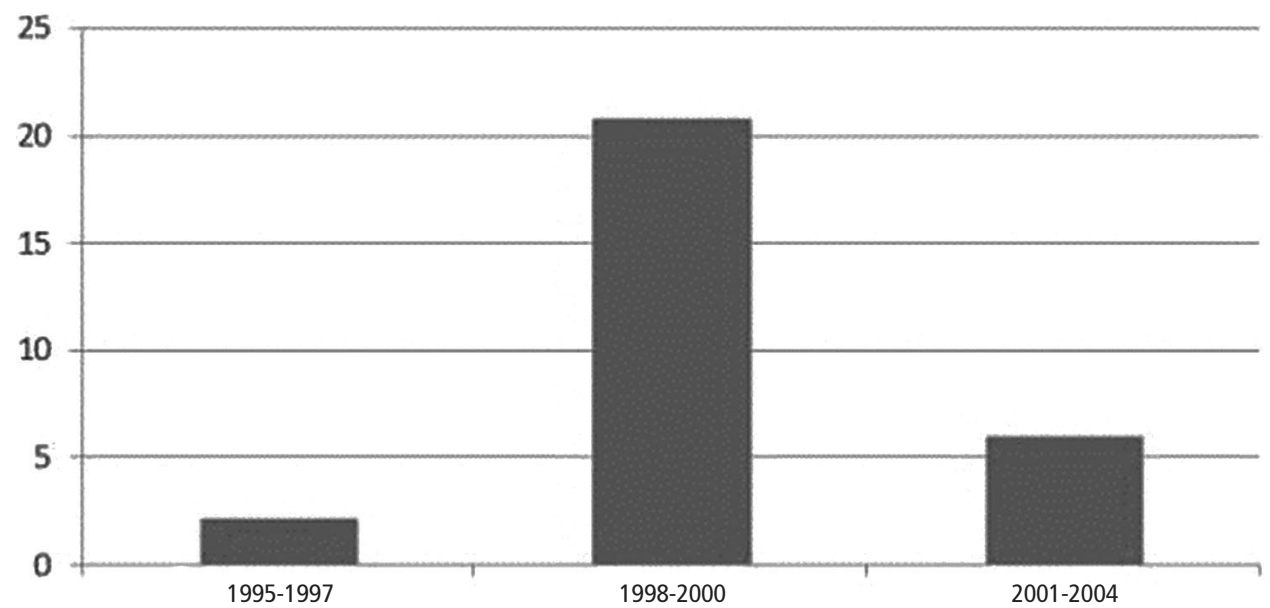

Fontes: Cálculos próprios baseados em dados da Câmara de Comércio de Bogotá (2005) para as despesas de capital e nos POAl fornecidos pela Dirección de Planeación do IDU em arquivo digital. 


\section{A definição socioespacial dos projetos de espaço público em Bogotá e no Rio de Janeiro}

A partir da análise dos instrumentos de gestão como planos de ordenamento, programas de governo e propaganda do governo local dos projetos foi possível estabelecer que, em ambas as cidades, as áreas urbanas como ruas, praças, parques, passarelas ou calçadões foram considerados pelas autoridades locais como elementos de espaço público. Porém, há uma grande diferença entre a construção do conceito e sua expressão espacial em termos de intervenções físicas no espaço urbano.

No Rio de Janeiro, os projetos de espaço público foram concebidos como parte de um projeto integral de requalificação urbana, de "acupuntura" de subcentros urbanos, em pontos específicos e corredores de áreas de grande centralidade em termos de sua "... alta densidade populacional, tráfego intenso, marcadas pela presença de instituições, comércio e serviços ou ainda reconhecidas por sua importância histórica" (Prefeitura do Rio de Janeiro, 1996, p. 3). 0 projeto denominado, em um primeiro momento, como Rio Cidade, e depois chamado de Urbe Cidade, incluiu atividades tais como "pavimentação de logradouros", "subterranização de infraestruturas de serviços públicos", "melhoria do sistema viário, de transportes e de circulação de pedestres", "definição de mobiliário urbano", "iluminação", "tratamento dos passeios", "tratamento paisagístico", "horário comercial dilatado", "comunicação visual (sinalização)" (1996, pp. 35-38).

Em Bogotá, o espaço público foi concebido a partir de uma visão mais sistêmica. Nos Planos de Ordenamento Territorial (POT), o espaço público é definido de forma bastante abrangente, de maneira tal que qualquer área de propriedade pública ou privada pode ser considerada pública se tiver impactos coletivos. No Decreto 619, primeiro POT da cidade (Alcaldía Mayor de Bogotá, 2000) são incluídas áreas como as calçadas, ruas e vias para veículos, mobiliários, infraestruturas de serviços públicos, os parques e ecossistemas naturais; além de fachadas e jardins exteriores dos prédios. Porém, as intervenções são mais diversas e não estão concebidas como um único projeto integral de requalificação como no caso carioca. Sua produção abrangeu ações tão diferentes como a requalificação da área central da cidade, realizada através de intervenções como o Eje Ambiental de la Avenida Jimenez e o parque Tercer Milenio, ações em subcentros urbanos, e a geração de espaços de suporte das infraestruturas de mobilidade do Transmilenio, até projetos específicos de importância local, como passarelas, calçadas ou áreas de lazer em diversos bairros da cidade.

Entretanto, existem divergências entre a definição formal e a execução dos projetos. É o caso das ruas dos bairros, cuja pavimentação é classificada pela instituição responsável, o IDU, como obra de infraestrutura local e não de espaço público. No mesmo sentido, ainda que na definição geral, áreas públicas construídas no marco de programas de legalização em zonas de origem informal sejam consideradas como espaço público, as instituições executoras as classificam sob outra categoria de investimento de infraestrutura urbana. No Rio de Janeiro, nem os programas de pavimentação de logradouros, nem os programas de integração de áreas de origem informal através de intervenções de urbanismo são concebidos como 
projetos de espaço público. Para os agentes políticos cariocas, a intenção era criar espaços comunitários para os vizinhos.

Essas divergências nas definições locais do que significa projeto de espaço público também se expressam no número de intervenções e no seu arranjo espacial. A partir do uso de ferramentas de análise espacial, procuramos localizar os projetos que tinham informação disponível. Particularmente empregamos a ferramenta de densidade de Kernel, ${ }^{4}$ que agrupa pontos de dados, neste caso de projetos, a partir de sua distância recíproca. Além disso, aplicamos uma análise de estatística espacial denominada análise de vizinhança, ${ }^{5}$ que procura estabelecer, a partir da análise da distância, se há padrões concentrados ou dispersos de localização.

Em relação ao número de intervenções, as diferenças em termos das classificações locais de espaço público são evidentes. Enquanto em Bogotá foram considerados 143 projetos, especificados pelo IDU em seus Planes Operativos Anuales de Investimento (POAI) como espaço público; no Rio foram 44 projetos, agregando o Rio Cidade e o Urbe Cidade. Quanto à localização desses projetos, nas duas cidades há coincidência na implantação em áreas consolidadas, mais densas, mais do que nas áreas de expansão e de crescimento urbano potencial. Privilegiou-se também nas duas cidades o fortalecimento dos centros antigos, onde se concentrou a maior parte dos investimentos. No Rio de Janeiro, o padrão desses projetos é mais concentrado. Com base nos resultados das análises de vizinhança ${ }^{6}$ e de densidade de Kernel, podemos identificar pelo menos três grandes áreas com a maior densidade dos projetos do Rio-Cidade e do Urbe-Cidade:
- Uma grande área linear, com sete projetos, que vai do centro da cidade até Copacabana, que inclui tanto a área central, composta pelo centro antigo (Largo da Carioca, Cinelândia), pelo núcleo central de negócios (Avenida Rio Branco) e pela área periférica do centro (Lapa e Riachuelo), com os bairros da zona sul Glória, Catete, Botafogo e Copacabana. Essas áreas são reconhecidas por seus valores paisagísticos e pelo seu potencial turístico, fato que poderia confirmar o argumento dos teóricos da geografia crítica relativo à promoção de projetos para favorecer a atratividade da cidade para mercados externos. Entretanto, também são espaços de moradia de uma porção importante da classe média carioca.

- Essa última característica também distingue os bairros que fazem parte da segunda área observada, que abrange a ampla zona da Tijuca, e que não estão plenamente incorporados aos circuitos turísticos da cidade. Áreas como a Praça Saens Pena na Tijuca, além do Grajaú, Vila Isabel, Haddock Lobo, Rua Uruguai e, um pouco afastados, Méier, Pavilhão e Lins de Vasconcelos, receberam um total de nove projetos.

- Uma terceira área identificada na análise inclui bairros da Zona Norte da cidade, tais como Irajá, Madureira, Realengo e, um pouco mais afastado, o bairro de Guadalupe. Essas áreas se distinguem por sua centralidade como espaços comerciais, de concentração de serviços e oferta e demanda de emprego para um setor importante do subúrbio carioca, de grupos de renda mais baixa (Côrrea, 1995) e que conformam núcleos secundários, especialmente o caso de Madureira. No total, essa área recebeu oito projetos. 
Identificamos um conjunto composto por áreas com menor densidade de projetos e com padrões mais dispersos, que inclui a Ilha do Governador, Campo Grande, na Zona Oeste, e Ipanema e Leblon, na Zona Sul. É possível notar que não há projetos na área da Barra da Tijuca, onde mora uma proporção significativa de grupos de renda mais alta, e que o número de intervenções é muito reduzido em grande parte da Zona Oeste, ambas caracterizadas como zonas de expansão.

Em Bogotá observa-se também um padrão de alta concentração de projetos, $^{7}$ embora com uma configuração diferente em razão dos processos socioespaciais que deram lugar à estrutura urbana atual. ${ }^{8}$ Como já assinalamos acima, a dispersão do número de projetos é maior. A partir da densidade de Kernel, é possível distinguir o seguinte padrão de concentração de projetos:

- Uma grande área que faz parte do centro expandido da cidade (2000). Essa área se caracteriza pelo padrão linear, paralelo aos cerros orientales da cidade. Sua ocupação foi resultado do crescimento urbano em sentido norte - sul e pela concentração de atividades

\section{Mapa 1 - Análise de concentração de projetos de espaço público na cidade de Rio de Janeiro (Projetos Rio-Cidade e Urbe-Cidade)}

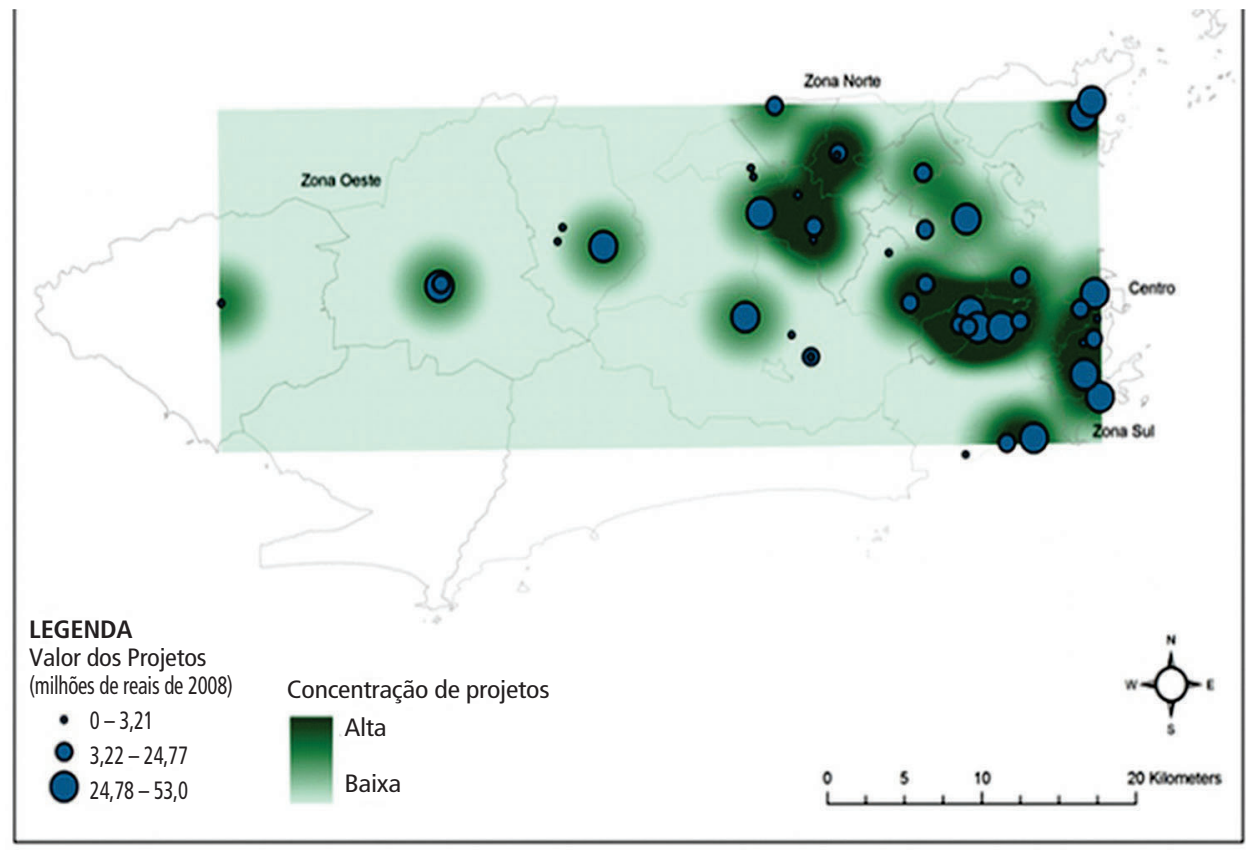

Fonte: Elaboração própria, baseada em dados da Secretaria de Obras Públicas. Prefeitura do Rio de Janeiro. Cobertura de regiões administrativas em formato shape. Armazém de dados do IPP, Prefeitura do Rio de Janeiro (2010). 
comerciais e de serviços. Inclui tanto o centro histórico da cidade, como o núcleo central de negócios e vários bairros de classe média. Essa área é percorrida pelas principais vias e servida pelo sistema Transmilenio.

- Uma segunda área compreende os bairros de Teusaquillo e Ciudad Salitre, na região oeste da cidade que receberam importantes intervenções, caracterizados por serem locais de moradia de setores médios e altos da cidade.

- Mais ao sul, encontramos uma terceira área que abrange os bairros da localidade de Kenne$d y$ e de Tunjuelito, de setores médios, médios baixos e baixos, com um número menor, mas ainda representativo de projetos.

Em geral, as seguintes áreas que fazem parte das áreas de expansão da cidade receberam um menor número de intervenções: a zona ocupada por setores pobres das localidades de Bosa e Usme ao sul da cidade; e a área que inclui as localidades de Fontibón e Engativá, ao oeste da cidade, habitadas por grupos de classes médias e médias baixas. Também foi o caso das localidades de Suba e Usaquén, norte da cidade, onde mora uma proporção importante de classes mais altas (ver Mapa 2).

Nas duas cidades uma proporção importante dos projetos está localizada nas áreas com maior densidade populacional, ${ }^{9}$ reafirmando a tendência de intervenções compreendidas como requalificação de áreas mais consolidadas. A análise também evidenciou que os projetos não necessariamente se orientaram em direção às áreas de expansão, nem de concentração de grupos mais abastados.
A construção local da definição da forma e significado espacial dos projetos de espaço público: entre a homogeneização e a diversidade

As diferenças na definição do projeto de espaço público em cada cidade superam o caráter quantitativo. É preciso avançar ainda mais em relação aos significados atribuídos a esses projetos, não a partir de uma definição normativa e abstrata, mas em termos de sua definição e significação espacial para cada contexto local. Uma definição preliminar dos projetos refere-se aos objetos como o mobiliário urbano, as áreas livres de praças, as calçadas, os calçadões, os parques, as ruas e as avenidas. Segundo essa perspectiva, em ambas as cidades foram destinados recursos importantes para sua produção. Entretanto, uma análise mais aprofundada de sua implantação evidencia diferenças relevantes.

Em relação à articulação dos objetos no espaço, observam-se propostas bem diferenciadas nas duas cidades. Enquanto no Rio de Janeiro as intervenções se caracterizaram pela formulação de um projeto urbano integral para cada área de implantação, visando o reforço da identidade dos bairros, em Bogotá há uma diversidade maior em relação ao tipo de intervenção, porém, com uma maior homogeneidade na proposta formal de desenho.

Os projetos cariocas caracterizaram-se, em primeiro lugar, pela requalificação de áreas centrais existentes e pelo reforço de novas centralidades. 0 projeto é concebido como uma 
Mapa 2 - Análise de concentração de projetos de espaço público na cidade de Bogotá (1998-2001)

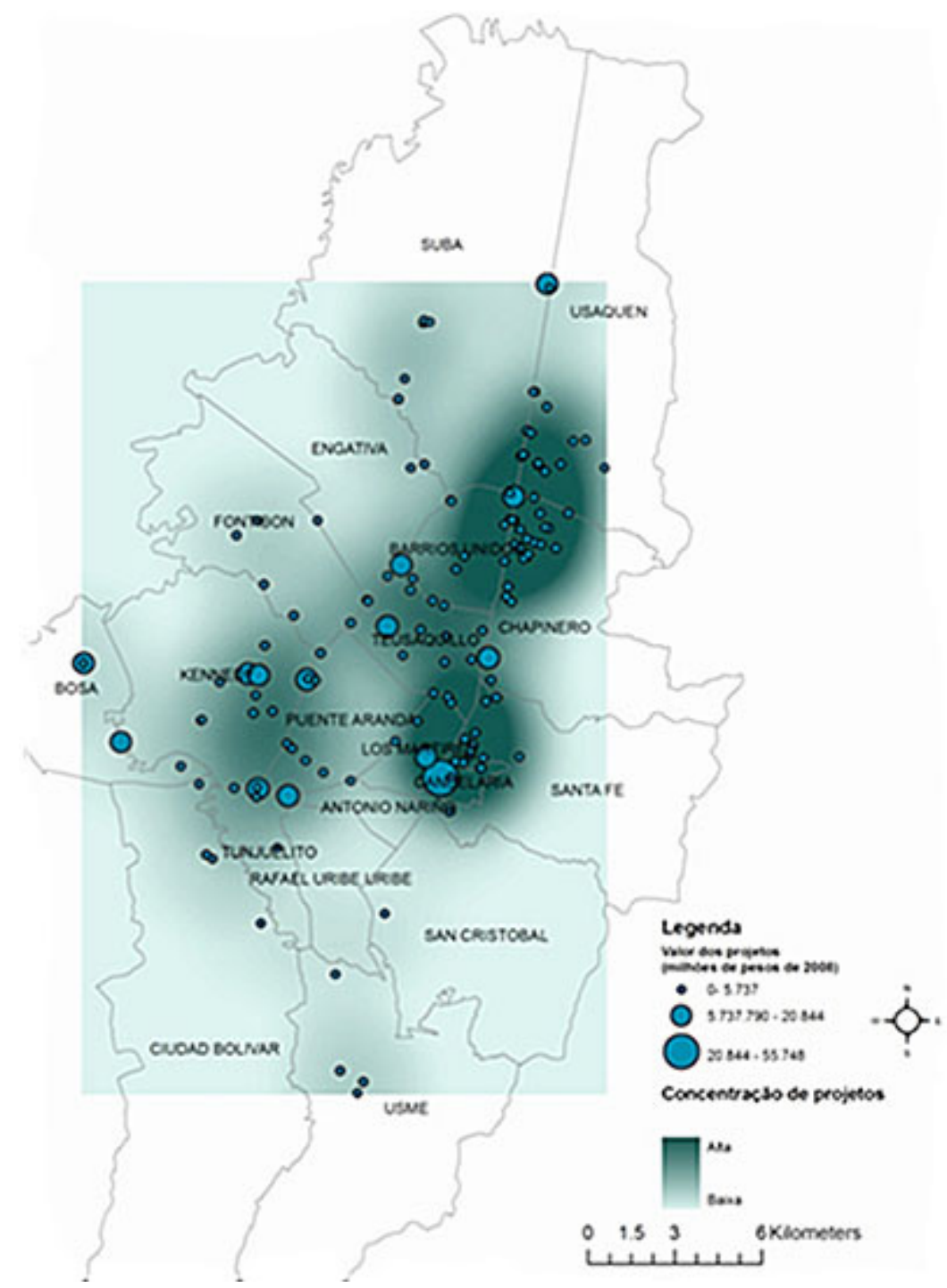

Fontes: Elaboração própria baseada em arquivos digitais fornecidos pelo IDU de POAI de 1995-2004. Cobertura de localidades de Bogotá: Secretaria Distrital de Planeación. Arquivo digital da SDP. Bogotá (2008). 
ação pontual de revitalização de áreas que haviam sofrido um forte processo de degradação e desordem urbana. De acordo com a visão dos gestores, essas obras geram custos mais baixos do que as grandes obras de renovação, além de menores impactos sobre o deslocamento de grandes contingentes populacionais. Segundo Cesar Maia e Luiz Paulo Conde:

Ao contrário da renovação que surge de um processo de rupturas traumáticas, 0 Rio Cidade inaugura a prática da revitalização urbana. Busca-se menos uma imagem ideal que a requalificação do tecido existente. Requalificar é, portanto, uma forma de reabilitar menos onerosa $\mathrm{e}$, principalmente, gradual. Caracterizando-se como um urbanismo heterogêneo e de múltiplas intervenções, o Rio Cidade, procura respeitar a singularidade de cada lugar, reforçando tendências e revisando desequilíbrios. (Prefeitura do Rio de Janeiro, 1996, pp. 26-28)

Em segundo lugar, esses projetos se distinguem pelo privilégio concedido à rua como unidade primária de intervenção, valorizada como o espaço do pedestre, da interação, do convívio e da intensidade de atividades. A rua é considerada como um elemento estruturador da vida urbana carioca:

Assim, elencaram-se, preliminarmente, gêneros de intervenções que melhorassem significativamente a qualidade de vida urbana, proporcionando a pedestres, idosos, crianças, gestantes e deficientes 0 desfrute das ruas, restituídas de seu caráter público, ações que tornassem a cidade um lugar mais adequado ao pleno exercício da cidadania e que, ademais, valorizassem o comércio estabelecido, motivassem a participação interessada dos beneficiados e embelezassem a cidade. (Ibid., p. 25)
Em termos espaciais, a rua é concebida como um elemento a partir do qual o crescimento da cidade, o tecido urbano e os bairros se organizam. 0 conceito de rua não se limita a um espaço formado por calçadas e áreas para a circulação viária. É definida em termos de uma área maior, denominada de trecho ou corredor urbano. Essa área abrange ruas, articuladas em torno de praças, as quais conferem o caráter de centralidade. Assim:

A ideia básica que norteou o projeto partiu da evidência de que o Rio é uma cidade constituída por "corredores", ou seja, acompanhando sua evolução urbana, é possível perceber que o crescimento do tecido edificado orientou-se por alguns eixos dominantes: antigos caminhos, linhas de bondes, estradas de ferro e rodovias... Fazendo dos corredores um princípio ordenador do projeto, tornou-se possível conceber a cidade como conjunto, partindo de sua própria historicidade, ou ainda, o próprio fato urbano, historicamente consolidado ganhou a condição de conceito operacionalizador capaz de possibilitar uma articulação entre o geral e o particular. (Ibid., p. 30)

Em terceiro lugar, os projetos têm como objetivo o ordenamento das atividades de sociabilidade pública. A partir das obras, almeja-se a reativação do comércio e das atividades culturais, de lazer e consumo, em condições de boa acessibilidade, segurança e relações de convívio. A proposta urbanística consiste na delimitação de usos diferenciados, mediante faixas específicas para o entretenimento passivo (bancas, coretos, etc.), entretenimento ativo (quadras para prática de esportes), comércio ambulante, e ordenamento da circulação de transporte público e privado, estacionamento e carga e descarga. Segundo esses gestores: 
A proposta é restituir ao morador e ao frequentador do bairro o livre trajeto e 0 fácil deslocamento, inclusive dos portadores de deficiência locomotora. Alguns projetos definem espaços exclusivos para o comércio ambulante, que deverá ser limitado ao número e usos definidos pela prefeitura. A maioria das propostas sugere a ordenação do uso das calçadas mediante a delimitação de faixas destinadas à circulação de pedestres, lazer e serviços. (Ibid., p. 38)

Em quarto lugar, as intervenções visam reforçar a identidade de bairro, lugar de destaque de elementos da memória histórica, que contribuem para a reconstrução da imagem do lugar. Mediante a disposição de elementos como mobiliário urbano, luminárias ornamentais, desenho das calçadas com motivos específicos e monumentalidade nas áreas centrais de intervenção se espera reconstituir a atratividade e a memória dos centros de bairro. Por exemplo, no projeto realizado no bairro de Vila Isabel, o realce na forma das calçadas e na monumentalidade tinha relação com a história de Noel Rosa, famoso cantor e compositor carioca. No Catete, foi associado à sede do Palácio de Governo, quando o Rio era capital do país. Em Copacabana, a ênfase recaiu sobre as figuras do mar no calçadão e a retirada dos camelôs. Uma das intervenções mais importantes correspondeu à requalificação do centro da cidade, com a melhoria de largos como da Cinelândia e da Carioca, da Avenida Rio Branco, entre outros. De acordo com os gestores:

Finalmente, costurando as intervenções anteriores, o projeto Rio Cidade reconstruirá os corredores centrais de dezenove bairros, ativando a sensação de pertencimento ao bairro, tão marcante entre os cariocas. (Ibid., p. 3)
0 reforço do particular, dos elementos singulares, foi matizado pela construção de uma imagem de um projeto conjunto a partir da instalação de alguns elementos comuns de mobiliário em diferentes áreas e do uso da pedra portuguesa nas calçadas. Essa decisão obedeceu também aos critérios de reprodutibilidade técnica e dos custos. Porém, esse viés constituiu mais um pano de fundo do que uma característica determinante, em virtude da preferência pelo destaque da individualidade do lugar. A realização de concursos arquitetônicos e urbanísticos e a contratação de escritórios de arquitetos diferentes para o desenho de cada um dos projetos constituíram a expressão administrativa dessa visão de projeto urbano.

Por último, os projetos enfatizaram a recuperação e a adequação da infraestrutura urbana de serviços públicos em trechos viários e praças. Assim, cada projeto previu a instalação de redes de drenagem, esgoto, energia elétrica, telefonia, pavimentação de calçadas e pavimentação asfáltica. De acordo com funcionários da Secretaria de Obras Públicas, essas intervenções foram as mais custosas e as que mais exigiram exercícios de coordenação interinstitucional. ${ }^{10}$

0 caso bogotano apresenta algumas descontinuidades importantes em relação ao que os gestores consideram um projeto de espaço público, ainda que os objetivos de melhoria da sociabilidade, acessibilidade, segurança e atratividade dos lugares prevaleçam. Em primeiro lugar, em Bogotá, os projetos de requalificação e renovação urbana ocorreram paralelamente. Ao contrário do Rio de Janeiro, os gestores de projetos de espaços públicos decidiram enfrentar os protestos e os grandes custos envolvidos no deslocamento da população, tanto de 
moradores como de comerciantes, especialmente no centro da cidade.

Durante os governos de Antanas Mockus e Enrique Peñalosa executaram-se importantes projetos tais como a renovação da Praça de San Victorino, ocupada por vendedores ambulantes e barracas de comércio, muitas das quais contavam com permissão de longa data da prefeitura. A criação de uma grande praça transformou significativamente a paisagem. Outro importante exemplo foi a renovação da área adjacente a essa praça, a poucos metros do Palácio de Nariño, sede do governo nacional, e do Palácio Liévano, do governo local. Essa área tinha sofrido um forte processo de degradação e se caracterizava pela presença de bocas de fumo, venda de armas e de peças roubadas de carros, armazéns de material de reciclagem e lugar de moradia de um grupo significativo de pessoas em situação de rua. A renovação dessa área trouxe como resultado uma transformação significativa de mais de 16 hectares em pleno centro da cidade.

Em segundo lugar, os projetos de requalificação urbana não foram concebidos sob uma ideia unificada de intervenção, em termos de um projeto integral. Ao contrário, foram articulados em termos de sua definição como objetos físicos. É possível identificar pelo menos dois tipos de projetos.

Em um primeiro grupo, incluímos as propostas de desenho caracterizadas pela definição de uma área de intervenção linear: vias comerciais em áreas centrais, calçadões, eixos viários do sistema de transporte de massa Transmilenio e ciclorrutas. Especialmente os eixos viários do sistema de Transmilenio, concebidos durante o governo de Enrique Peñalosa, sob o conceito de troncales caracterizam-se por sua proposta de criação de espaços públicos, que incluem passarelas, praças, pontos de ônibus, ciclovias, calçadas, além de mobiliário urbano, iluminação pública e arborização especializada. As ciclovias constituem parte importante da proposta de espaço público da cidade. Esses objetos físicos foram construídos dividindo o espaço com os pedestres nas calçadas e resultaram na instalação de elementos de sinalização vertical e horizontal, delimitação da área de circulação, passarelas e facilidades para a circulação. Para sua implantação foi elaborado o Plan Maestro de Ciclorrutas, que definiu os critérios técnicos e operacionais do projeto. Durante o governo de Peñalosa foram construídos mais de $120 \mathrm{~km}$ aos quais foram acrescidos mais 30\% na gestão de Antanas Mockus (Berney, 2006, p. 4).

Em um segundo grupo, classificamos os projetos caracterizados por privilegiar áreas mais específicas, tais como praças, parques urbanos ou de conservação ambiental. As praças foram definidas como superfícies destinadas ao convívio e à sociabilidade, enquanto os parques e as áreas de conservação combinam superfícies para quadras de esportes com zonas verdes e arborização. Durante o governo de Antanas Mockus foram construídos 67 parques, 474 pequenos parques e 41 áreas verdes. No governo de Peñalosa, foram construídos 877 parques pequenos (menores de $1 \mathrm{Ha}$ ), 16 parques zonais e 19 foram reformados. A maior parte desses investimentos, $80 \%$, foi feita em setores de classes média e baixa (Cubaque, 2009, pp. 90-91).

Entre as praças mais importantes construídas ou renovadas nesse período podemos mencionar, no centro da cidade: a Plaza de San Victorino, o Parque Tercer Milenio, o Parque del 
Renacimiento (numa antiga área ocupada pelo Cemitério Central) e o Parque da Independência. Os parques El Salitre, Timiza, Simón Bolívar, Engativá, na zona oeste da cidade. 0 parque El Virrey, na área norte e o Parque Mirador de los Nevados na zona noroeste, em zonas nobres da cidade. As praças 20 de Julio, centro de romeiros, o parque el Tunal, el parque Entre Nubes, todos no sul da cidade.

Em terceiro lugar, ainda que haja uma grande diversidade de projetos, observa-se uma forte articulação na proposta de desenho formal, visando a homogenização dos espaços numa imagem única para toda a cidade. Essa articulação é produto da elaboração de um conjunto de critérios construtivos, adotados nos arranjos normativos, que dizem respeito às condições de implantação dos espaços, aos materiais empregados para sua construção, assim como também à centralização dos processos de desenho urbano nas mãos do Taller Profesionaldel Espacio Público formado por arquitetos da Sociedad Colombiana de Arquitectos, no âmbito do Departamento Administrativo de Planeación Distrital. ${ }^{11}$

Esses critérios de desenho são defendidos também como uma forma de ordenar a cidade, em virtude da necessidade de se produzir industrialmente materiais e peças de mobiliário que diminuam os custos para a administração local e para os diferentes agentes privados, além de facilitar a manutenção e criar, de forma intencional, uma imagem homogênea, em termos de sua estrutura e composição. Assim, foi adotado um manual para todo o espaço público da cidade. No mesmo sentido, definem-se as disposições referentes ao desenho do mobiliário, já que o manual sinaliza a intenção de gerar uma imagem própria para a cidade, caracterizada pela unidade e continuidade espacial, razão pela qual deve ser estabelecido um modelo único orientado pela simplicidade, neutralidade, funcionalidade, durabilidade, conforto e robustez, como constam no Decreto Distrital 170 de 1990 (IDU, 2000).

Ao contrário da proposta carioca, baseada na identidade dos bairros, onde cada projeto foi desenhado por um grupo consultor diferente, os projetos bogotanos promovem uma visão integradora do desenho urbano, a partir da continuidade formal dos espaços da cidade. Dessa forma, os elementos do mobiliário, as calçadas ou passarelas aparecem como um pano de fundo bastante neutro, sem destaque particular. Só alguns lugares de importância metropolitana ganharam objetos capazes de romper com essa continuidade por meio da instalação de monumentos, do paisagismo ou do desenho arquitetônico de equipamentos.

\section{Considerações finais}

A partir desses resultados, é possível identificar algumas continuidades relativas à importância atribuída ao espaço público. Em primeiro lugar, os dados evidenciam que nas duas cidades 0 espaço público desempenhou um papel significativo em relação a outros investimentos, de tal forma que os prefeitos não só valorizaram esse bem nos seus discursos e nos arranjos normativos, como na distribuição dos recursos públicos disponíveis. A incorporação desses bens tanto nos orçamentos, como nos instrumentos de planejamento, gestão e execução da política pública urbana expressa o importante papel dos processos de difusão dos modelos urbanos globais, em especial do planejamento 
estratégico catalão. A influência do modelo é evidente tanto nos discursos produzidos pelos diferentes agentes locais das duas cidades, como na própria destinação de recursos do orçamento local.

Porém, esse papel não foi constante. Ao contrário, esses mesmos indicadores e a análise dos arranjos espaciais dos projetos executados permitem observar diferenças nos ritmos de investimento, como na particular definição que foi produzida em cada cidade da categoria de espaço público e da sua função urbana e política. É possível identificar então um período de maior concentração, seguido por uma queda relativa de sua participação nas despesas de capital, particularmente na última parte do período estudado. Nos períodos posteriores, os projetos de espaço público não só perderam peso nos orçamentos, como na própria constituição dos programas de governo, em favor de maiores investimentos em programas sociais, como no caso de Bogotá, ou de fortalecimento da segurança pública, melhoria de infraestruturas de mobilidade e investimento em eventos esportivos, no caso do Rio de Janeiro. Desse modo, é possível concluir que a apropriação das propostas dos catalães não foi institucionalizada como uma política de longo prazo e, pelo contrário, esteve submetida a críticas por outros agentes urbanos que pretendiam favorecer outros tipos de bens públicos.

Os dados também contribuem para a identificação de algumas características específicas do desenvolvimento da política local, que permitem discutir a ideia de reprodução mecânica e de determinismo dos modelos urbanos promovidos na escala global. As diferenças na construção do conceito, como no tipo, número e forma das intervenções evidenciam a especificidade local na leitura do planejamento estratégico. Em Bogotá os agentes políticos especializados se apropriaram da categoria de espaço público como um eixo estruturante da política urbana de maneira semelhante à visão que autores como Borja promoveram, em relação à permanência e transversalidade desta categoria nas diversas ações de governo. Este caráter mais institucionalizado tem desdobramentos na construção de um projeto e de uma imagem de cidade na qual se valorizou a ideia de cidadania baseada na homogeneidade de seus espaços públicos, no intuito de diminuir a desigualdade e produzir um ideal de ordem urbana. No entanto, difere do modelo europeu o fato de promover projetos baseados no investimento público, mais do que em parcerias público-privadas, como promovido por esse.

No Rio de Janeiro parece existir uma variabilidade maior tanto em termos dos ritmos de investimentos, como no desenho formal dos lugares. Os prefeitos, em razão de suas decisões estratégicas, só os divulgaram durante um período e nos seguintes reduziram os investimentos até quase eliminá-los de suas preferências. Os projetos tiveram então um caráter mais conjuntural. De outro lado, os prefeitos elaboraram um plano estratégico e estabeleceram parcerias com o setor privado em alguns setores. Em relação à forma, os agentes cariocas promoveram intervenções que geravam a valorização da singularidade de cada lugar, dos centros de bairro e da identidade local. Promoveu-se, então, uma imagem de cidade baseada na diversidade cultural do carioca, com um ideal de ordem baseada na animação sociocultural, como reivindicado pelos planejadores catalães. 
Esses resultados colocam em evidência como a apropriação de cada modelo é resultado dos diálogos entre os agentes globais e locais, nos quais se articulam as diversas escalas em cada contexto urbano. A apropriação dos modelos está mediada por fatores políticos, físicos, sociais e históricos, os quais contribuem na construção de formas de classificação e entendimento da realidade pelos agentes políticos locais. Cabe a outras pesquisas elucidar os arranjos entre os governos e a cidadania que permitiram a legitimação desses projetos e suas transformações no marco de uma concorrência e negociação permanente das relações de poder. Pode-se dizer então que as escalas constituem marcos de interpretação e de ação social e espacialmente construídos.

\section{Ana Marcela Ardila Pinto}

Universidade Federal de Minas Gerais, Faculdade de Filosofia e Ciências Sociais, Departamento de Sociologia. Belo Horizonte/MG, Brasil.

marardila@gmail.com

\section{Notas}

(1) Nas duas cidades esses setores atingiram valores superiores a 30\%. Em Bogotá, entre 1995 e 2005, representaram em média de 49\% do total e, no Rio de Janeiro, entre 1991 e 2008, 37\%.

(2) No caso do Rio de Janeiro, foi empregada uma curva de tendência com uma média móvel de 4 para atenuar os grandes contrastes nos dados para os setores de governo e outros.

(3) Não foram incluídos os dados relativos aos parques urbanos visto que não se dispunha de uma série razoável para comparação. Lamentavelmente também não foram obtidos dados correspondentes aos períodos anteriores, os quais teriam permitido construir uma série mais completa.

(4) Esta ferramenta estabelece uma superfície uniforme para cada ponto, um raio circular de busca ao qual se sobrepõem os pontos situados mais próximos ao centro. Assim, os lugares mais concentrados aparecem em uma cor mais escura (ARCGIS, 2011)

(5) A análise de vizinhança calcula um índice de proximidade a partir da distância média entre as entidades e realiza provas $Z$ de diferença de proporções. Empregamos um índice de distância de Manhattan que, diferente da distância euclidiana, leva em consideração a configuração em blocos da cidade e mede a relação entre dois pontos situados ao longo de eixos e ângulos retos (2011). Embora o Rio de Janeiro não apresente uma forma regular em "tabuleiro xadrez", os bairros tendem se agrupar mais em blocos do que em linhas retas. 
(6) A partir de uma análise estatística de vizinhança estabelecemos que existe um nível de aglomeração de pontos com um nível de significância de 0,005. A distância média esperada é de 0,82 e o valor $Z$ foi de $-2,32$ de desvio padrão.

(7) A partir da análise estatística de vizinhança espacial, podemos assinalar que há um nível de aglomeração de pontos, com um nível de significância de 0,005. A distância média esperada é de 0,71 e o valor $Z$ foi de $-6,65$ desvio padrão

(8) Bogotá é constituída por 20 localidades, ou divisões de ordenamento político e administrativo que fazem parte do processo de descentralização urbana.

(9) Para distinguir os padrões espaciais no período de estudo, empregamos as estatísticas de densidade populacional correspondentes ao censo de 2000 no Rio de Janeiro e de 1993 de Bogotá.

(10) Comunicação pessoal concedida por Célio Pereira da Silva, funcionário da Secretaria de Obras Públicas, Coordenador do projeto Rio Urbe em setembro de 2009, no Rio de Janeiro.

(11) O Taller foi criado pelo Decreto Distrital no 324, de 1992, no período do prefeito Jaime Castro para definir as diretrizes para a produção, gestão e preservação do espaço público (1992). Em 1999, suas funções são assumidas pelo IDU e pela Defensoría del Espacio Público.

\section{Referências}

ALCALDÍA MAYOR DE BOGOTÁ (29 de maio de 1992). Decreto Distrital n. 324. Acesso em: 15 out 2010. Disponível em: Régimen legal de Bogotá. Compilación de normatividad, doctrina y jurisprudencia. Disponível em: http://www.alcaldiabogota.gov.co/sisjur/normas/Norma1.jsp?i=1824. Acesso em: 10 jan 2010.

(2000). Informe de Gestión: Estamos creando una nueva ciudad. Bogotá, Alcaldía Mayor de Bogotá.

BERDOULAY, V. e MORALES, M. (1999). Espace public et culture: stratégies barcelonaises. Géographie et cultures, n. 29, pp. 79-96.

BERNEY, R. (2006). Constructing sustainability: emerging spaces in Bogotá's search for a new identity. In: 2006 BRESLAUER GRADUATE STUDENT SYMPOSIUM, THE RIGHT TO THE CITY AND THE POLITICS OF SPACE. International and Area Studies. Anais. Berkeley, University of California, pp. 1-7.

BIENESTEIN, G. (2000). Espaços metropolitanos em tempos de globalização: um estudo de caso do Rio de Janeiro. Tese de Doutorado. Rio de Janeiro, Universidade Federal do Rio de Janeiro.

BORJA, J. e MUXI, Z. (2003). El espacio público: ciudad y ciudadanía. Barcelona, Electa.

BOTELHO, A. (2004). A produção do espaço e o empresariamento urbano: o caso de Barcelona e seu Fórum das Culturas de 2004. Espaço e Tempo. Geousp, n. 16, pp. 111-124.

BOYER, C. (1992). "Cities for sale: Merchandising history at South Street Seaport". In: SORKIN, M. (org.). Variations on a theme park. The new american city and the end of public space. Nova York, Hill and Wang. 
BRENNER, N. (1998). Global cities, global states: global city formation and state territorial restructuring in contemporary Europe. Review of International Political Economy, v. 5, n. 1, pp. 1-37.

CÁMARA DE COMERCIO DE BOGOTÁ. (Diciembre de 2005). Observatorio de Finanzas Públicas Distritales. Disponível em: http://camara.ccb.org.co/documentos/892_2006_6_22_9_30_37_ obs_finanzas4.pdf. Acesso em: 10 out 2010.

CICCOLELLA, P. (1999). Globalización y dualización en la Región Metropolitana de Buenos Aires: grandes inversiones y reestructuración socioterritorial en los años noventa. Eure. Santiago, v. 25, n. 76, pp. 5-27.

CONTROLADORIA GERAL DO MUNICÍPIO DO RIO DE JANEIRO. (2010). Contas Públicas do Município do Rio de Janeiro. Disponível em: http://www7.rio.rj.gov.br/cgm/contadoria/Irf/. Acesso em: 10 out 2010.

CÔRREA, R. L. (1995). O espaço urbano. Rio de Janeiro, Ática.

CUBAQUE, C. (2009). La influencia de la construcción y recuperación del espacio público físico en los procesos de fortalecimiento y formación de ciudadania. Monografia. Bogotá, Universidad del Rosario.

DOMINGUES, L. C. (1999). Projeto urbano e planejamento: o caso do Rio Cidade. Tese de Doutorado. Rio de Janeiro, Universidade Federal do Rio de Janeiro.

DUQUE, I. (2008). Planeamento urbano en Bogotá 1994-1997. La construcción de un modelo. In: Geocrítica (ed.), Actas del X Coloquio Internacional de Geocrítica. Universidad de Barcelona. Barcelona, Geocrítica

HARVEY, D. (2006). “The political economy of public space”. In: LOW, S. e SMITH, N. (orgs.). The politics of public space. Nova York, Routledge Taylor \& Francis Group.

HIERNAUX, D. (2006). “Los centros históricos: espacios posmodernos? (De choques de imaginarios y otros conflictos)”. In: LINDÓN, A.; AGUILAR, M e HIERNAUX, D. Lugares e imaginarios en la metrópolis. Iztapalapa, Anthropos.

HOWITT, R. (2007). "Scale". In: AGNEW, J.; MITCHELL, K. e TOAL, G. (orgs.). A companion to political geography. Oxford, Blackwell Publishing.

INSTITUTO DE DESARROLLO URBANO (2000). Cartilla de mobiliario urbano. Disponível em: http://idu. gov.co/web/guest/tramites_doc_manuales. Acesso em: 20 out 2010.

(2000). Gestión 2000. Nuevo concepto de ciudad. Bogotá, Alcaldía Mayor de Bogotá.

INSTITUTO DE PESQUISA ECONÔMICA APLICADA. (2011). Instituto de Pesquisa Econômica Aplicada. IPEA. Disponível em: Data:http://www.ipeadata.gov.br/ipeaweb.dll/ipeadata?SessionID=11909 86098\&Tick=1297522711553\& VAR_FUNCAO=Ser_Temas(125)\&Mod=R. Acesso em: 20 jan 2011.

INSTITUTO PEREIRA PASSOS (1998). Anuário estatístico da cidade do Rio de Janeiro. Rio de Janeiro, Instituto Pereira Passos.

LINDÓN, A.; HIERNAUX, D. e AGUILAR, M. (2006). “De la espacialidad, el lugar y los imaginarios urbanos: a modo de introducción”. In: LINDÓN, A.; HIERNAUX, D. e AGUILAR, M. (orgs.). Lugares e imaginarios en la metrópolis. Iztapalapa, Anthropos.

LOW, S. e SMITH, N. (orgs.). (2006). The politics of public space. Nova York, Routledge Taylor \& Francis Group. 
MACHADO, V. F. (2003). Compreendendo o urbano: O marketing político na cidade do Rio de Janeiro. Dissertação de Mestrado. Rio de Janeiro, Universidade Federal do Rio de Janeiro.

MITCHELL, D. (2003). The right to the city. Nova York, The Guilford Press.

MOORE, A. (2008). Rethinking scale as a geographical category: from analysis to practice. Progress of Human Geography, n. 32, pp. 203- 225.

OLIVERA, M. P. (2008). Projeto Rio Cidade: intervenção urbanística, planejamento urbano e restrição à cidadania na cidade do Rio de Janeiro. Diez años de cambios en el Mundo, en la Geografía y en las Ciencias Sociales, 1999-2008. Scripta Nova. Revista Electrónica de Geografía y Ciencias Sociales de la Universidad de Barcelona, v. XII, n. 170.

ORTIZ, A. (2006). "Uso de los espacios públicos y construcción del sentido de pertenencia de sus habitantes en Barcelona". In: LINDÓN, A.; AGUILAR, M. e HIERNAUX, D. (orgs). Lugares e imaginarios en la metrópolis. Iztapalapa, Anthropos.

PARDO, M. (2008). Territorialidades cívicas. Espacio público y cultura urbana en Bogotá, Colombia. Bogotá, Universidad Externado de Colombia.

PIRES, H. F. (2010). Planejamento e intervenções urbanísticas no Rio de Janeiro: a utopia do plano estratégico e sua inspiração catalã. Biblio 3W. Revista Bibliográfica de Geografía y Ciencias Sociales, Universidad de Barcelona. Barcelona, v. XV, n. 895. Disponível em: http://www.ub.es/ geocrit/b3w-895/b3w-895-13.ht.

PREFEITURA DO RIO DE JANEIRO (1996). Rio Cidade: o urbanismo de volta à rua. Rio de Janeiro, Prefeitura do Rio de Janeiro.

PULICI, A. P. (2006). Intervenção pública na década de 90: uma análise dos impactos espaciais do Programa Rio-Cidade no mercado imobiliário da cidade do Rio de Janeiro. Dissertação de Mestrado. Rio de Janeiro, Universidade Federal do Rio de Janeiro.

SALAZAR, J. (2008). Bogotá, 1992-2005. The reversal of the crises and the planning scheme. Tóquio, Universidade de Tóquio.

SANTOS, R. (2007). Bogotá: el colapso de una maquinaria política. Economic Analysis Working Papers, v. 6 , n. 13 , pp. $2-28$.

SARTOR, C. E. (2001). Imagem da cidade - cidade da imagem: o modelo de intervenção urbana do Rio Cidade. Cadernos Metrópole, São Paulo, n. 4.

SWYNGEDOUW, E. (2004). "Scaled geographies: nature, place, and the politics of scale". In: SHEPPARD, E. e MCMASTER, R. (orgs.). Scale and geographic inquiry: nature, society, and method. Malden, Blackwell Publishing.

TURNER, R. (2002). The politics of design and development in the postmodern downtown. Journal of Urban Affais, v. 24, n. 5, pp. 533-548.

ZUKIN, S. (1995). The cultures of cities. Oxford, Blackwell Publishing.

Texto recebido em 27/jan/2015

Texto aprovado em 26/jul/2015 